\title{
6 \\ If the market is the problem, is the hybrid economy the solution?
}

\author{
Katherine Curchin
}

\section{Introduction}

One of Jon Altman's preoccupations in recent years has been the impact of neoliberal ideology on Indigenous affairs policy. He has been a critic of the policy goal of incorporating more Indigenous Australians in remote regions into the mainstream economy, believing that Indigenous Australians joining the labour market are destined for the least desirable place within it. He has also argued that the values orientation promoted by market society is at odds with the kin-based societies in which many Indigenous people live today. Altman maintains that an ideological commitment to the market has blinded many policymakers to the viable alternatives to market-based development in Australia's north (Altman 2005: 122). His hybrid economy framework challenges the dominant way of thinking about economic development for Indigenous peoples by highlighting a range of productive activities currently performed by Indigenous groups in Australia's north. These innovative activities occur within the intersection of the customary, market and state sectors of local economies. Livelihood strategies based on these activities enable 
Indigenous people who live in regions remote from urban centres to generate income while resisting the full commoditisation of their labour and their land.

Scholars from a range of disciplines have found Altman's hybrid economy model useful in analysing past and present regional economies (Smith 2003, Gill 2005, Kwan et al. 2006, Lloyd 2010, Holcombe et al. 2011, Sullivan 2011, White 2011). The distinctive approach to Indigenous development that Altman has derived from the hybrid economy model has also been embraced with enthusiasm by some scholars (Morphy 2008, Scambary 2009, Watson 2009, Howitt 2012, Buchanan 2014), but there remains a need for further scholarly interrogation of the strengths and weaknesses of this approach. This chapter responds to this need by asking whether the hybrid economy offers a convincing way of resolving the tension Altman identifies between Indigenous cultural dispositions on the one hand and the attitudes and priorities underpinning market society on the other. In particular it grapples with what might appear to be a paradox: that protecting non-market values associated with Indigenous lifeworlds can best be achieved by focusing on the articulations of the customary economy with the market.

This chapter begins by examining the ways in which 'the market' or to be more precise, development approaches underpinned by an ideological fixation on markets - figures in Jon Altman's writings as a problem for Indigenous peoples. I then examine the key characteristics of the livelihood activities at the core of Altman's hybrid economy approach to Indigenous development. I argue that the concept of partial commodification is useful for understanding what is appealing about these activities. My articulation of the concept of partial commodification draws on the work of the political philosopher Elizabeth Anderson (1993). She uses the notion of partial commodification to defend hybrid institutions in which the norms of the market are co-present with non-market norms derived from spheres such as the arts, the academy, sport and medicine. The desire of artists, academics and other professionals to make a living while resisting the full commodification of their talents finds a parallel in the aspiration of Indigenous people to make a living while resisting the full commodification of their unique knowledges, skills, traditions and lands. 
Emphasising that partial commodification is at the core of the hybrid economy model is important because it averts a possible misinterpretation of Altman's approach. Altman is not blindly endorsing all articulations of the customary with the market or state. Partial commodification of Indigenous practices opens up opportunities, but as Altman recognises, it also poses dangers. In light of this I make some brief remarks in the final section of this paper about the 'bliss point' of the hybrid economy, a concept surrounding which there seems to be some misunderstanding.

\section{The problems with markets}

Altman takes issue with policymakers' faith in the power of labour market engagement to lift Indigenous Australians out of poverty and improve their well-being. He insists there are 'structural and other impediments that will limit the overall growth of the market in the remote regions where Indigenous people live on Aboriginal land' (Altman 2001: 8). The contemporary effects of the historical barriers Indigenous Australians have faced in accessing education and employment opportunities reduce their prospects of securing wellrewarded work. In remote regions in which the great majority of the Indigenous estate is located, the conditions necessary for the efficient operation of markets (such as a sufficiently large pool of buyers and sellers) are not present. Moreover, he observes that the reason these areas remained unalienated by settlers, and were therefore available for claim by Indigenous groups within the processes of the settler legal system, was their lack of promise as sites of commercial development (Altman 2001: 2). Yet many Indigenous people still aspire to live on (or close to) their ancestral lands located beyond the reach of a functioning labour market. This prompts Altman to take seriously the need for alternative means of alleviating Indigenous poverty.

At the same time Altman exhibits a further concern about marketoriented solutions to Indigenous poverty. As other economic thinkers have recognised, markets promote a distinctive ethos (Bowles 1998). This ethos entails certain conceptions of personhood and sociality which conflict with the distinctive Indigenous forms of personhood and sociality Altman has observed during fieldwork in central Arnhem Land. The contrast between market societies and kin-based 
societies is vital to Altman's critique of market-based development. Before proceeding further it is worth making the nature of this distinction clear.

Within market societies many interactions are relatively short-lived and impersonal, consisting of mutually beneficial trade facilitated by money. People are encouraged to think of themselves as individuals and as competitors. They are expected to invest in human capital - in other words, the education and occupational skills of their children and themselves. Adults derive a sense of personal identity from their job role. They surrender some of their autonomy to the will of their employer or else run enterprises shaped by the demands of their customers. The accumulation of material wealth is treated as honourable. Economic dependence on others is stigmatised. Saving and budgeting are prioritised over meeting the immediate needs and wants of extended kin.

By contrast, in kin-based societies such as those Altman has documented, personal interactions are among networks of kin. The sense of self is larger than the individual.

Personal identity is derived from relationships with people. The accumulation of material wealth is treated as dishonourable. People are less willing to sacrifice autonomy by submitting to authority for the sake of material gain. Economic interdependence with others is viewed positively. Meeting the immediate needs of self and kin is prioritised over saving and budgeting.

Altman considers economic development policies predicated on the displacement of a customary ethos with a market ethos ill-advised. He views such policies as assimilationist and therefore unjust. Altman also appears sceptical that top-down attempts to shift Indigenous conceptions of personhood and sociality will actually work. In other words, these social forms might prove more resilient than governments anticipate. In Altman's judgement the shift in worldview that successful competition in the mainstream labour market demands cannot be made without great suffering. The unsatisfactory gains likely to come from full integration into the market economy make this painful process seem all the more unfair. The hybrid economy is designed to address at once both these problems with market-based approaches to Indigenous development. 


\section{The hybrid economy approach}

The foundational premise of the hybrid economy approach is that the regional economies within which some Indigenous Australians today make a living are comprised not just of the market and state sectors but of a third, often overlooked sector: the customary sector. These three sectors do not merely coexist but interact to make possible a range of distinctive livelihood opportunities (see Curchin 2013: 18-9). Of the livelihood opportunities that groups of Indigenous people have chosen or might choose to pursue in the future, Altman has particularly sought to draw attention to those which:

1. Provide an income.

2. Give working-age people something productive to do.

3. Support the continuation of distinctively Indigenous forms of personhood and sociality.

Livelihood opportunities which meet these three criteria are at the core of Altman's distinctive approach to Indigenous development. The productive activities most associated with the hybrid economy approach to Indigenous development are:

- self-provisioning through hunting and gathering;

- wild harvesting for sale of bush foods, marine species, native wildlife and introduced species;

- production for sale of Indigenous art, crafts and artefacts;

- environmental management services including ecological monitoring and research, fire management, invasive weed control, feral animal management and marine debris collection;

- cultural heritage management; and

- cultural tourism, festivals, and performances such as dance, music and storytelling.

These activities share a number of important features. The most noteworthy is that they enable people to reside on or close to their ancestral land and to maintain a valued connection with a sentient landscape. They use resources from the local environment in ways which can be sustained. 
All but the first are a source of cash: they involve using the comparative advantage derived from customary and local knowledge and identity to produce goods or services for sale or payment. At the same time these activities provide opportunities to pursue distinctly Indigenous purposes - such as fulfilling obligations as traditional custodians of particular areas of land. The motivations for engaging in these activities go beyond cash remuneration, for example, the opportunities they provide to visit hard-to-access places. All of these activities entail the use and development of ecological, cultural or linguistic knowledge and skills derived from the Indigenous domain. They create opportunities to transmit this knowledge and identity to younger generations, and to receive recognition from outsiders of their mastery and their cultural survival in the face of colonisation. In comparison with conventional forms of employment, there is more scope for self-direction and less emphasis on submission to the will of an employer. The timing and duration of work effort is less likely to be organised around clock-time and the Western calendar and more likely to reflect ecological and ceremonial cycles. Work practices depend upon cooperation rather than competition with other workers within the workplace. Work groups are likely to be comprised of people whose kin-relationships make them comfortable working together. In sum, these activities enable people to earn income-including cash income derived from market exchange-while resisting the full commoditisation of their labour, their cultural inheritance or the local environment.

Many of the activities at the core of the hybrid economy approach involve the state as well as the customary and market sectors. These activities are too small scale, too labour intensive, too seasonal or too geographically remote from markets to attract private capital investment or to be economically profitable without government or philanthropic subsidisation through funding of, for example, equipment or marketing expertise.

Other activities that share many of these characteristics but feature less prominently in the hybrid economy literature, if at all, include:

- monitoring Australia's borders on behalf of the Australian Government;

- running cattle stations;

- translating, interpreting and teaching Indigenous languages; 
- media production including film, television, radio and digital media;

- social, cultural and linguistic research; and

- providing consulting services in fields such as bush survival, bush pharmacology and cultural awareness.

It is important to note that the productive activities at the core of the hybrid economy approach to development are only a subset of the activities through which Indigenous people residing in remote regions earn a cash income. Municipal services, road building and repair, construction and building maintenance, transport, food and alcohol retail, mining, health services, school education, childcare, disability care and aged care, as well as government and non-government administration are all industries providing some employment for Indigenous people in remote regions. Though technically all part of the hybrid economies of these regions, these avenues for making a living are not at the core of the hybrid economy development approach because they meet the first two criteria I outlined above but not the third. Whether Altman is wise to place such emphasis on the third criteria is a matter of debate (see Austin-Broos 2011: 122-3, 141-5), but I do not have the space to engage with this issue here.

\section{Partial commodification}

The concept of partial commodification - familiar to non-Indigenous people from fields of endeavour such as medicine, science and the artsis useful for thinking about the livelihood activities which typify the hybrid economy. It also illuminates some of the current threats to these activities. Though goods such as artwork, artefacts and crocodile eggs, and services such as weed control, fire management and cultural tours are exchanged for money, this does not necessarily mean they become mere commodities, mere instruments of profit and use. Rather, as Elizabeth Anderson argues, 'what confers commodity status on a good is not that people pay for it, but that exclusively market norms govern its production, exchange, and enjoyment' (Anderson 1993: 156). Even when goods and services are produced for sale, criteria other than profitability may be used to make decisions. Commodification need not be all or nothing; it admits of degrees. This is important because the full commodification of certain types of goods degrades them. 
This thought has been central to the development of professions in the West. Professions have traditionally been characterised by the honouring of non-market values. Even though money changes hands, market norms are not the only norms governing the interaction. Ethical judgements are also in play, and may at times trump considerations of profitability. Artists and scholars too derive their livelihoods from the partial commodification of their talents. They accept payment for their efforts yet still recognise aesthetic values and truth-seeking as guiding ideals. Honouring such ideals will sometimes entail forgoing opportunities to make money (Anderson 1993: 147). Partial commodification is not to be regretted according to Anderson: it is important that professionals, artists and scholars can be paid for their work, because this is what enables them to devote most of their productive hours to it without sliding into destitution. Though the engagement of market and non-market spheres creates potential for conflict, this does not rule out the possibility of arrangements that are mutually beneficial.

When thinking about the hybrid economy it is helpful to remember that Indigenous Australians are not alone in seeking engagement with the market without total colonisation by market norms. Just as there are Indigenous people who wish to make their livelihoods while honouring standards deriving from a local Indigenous value system, there are professionals who make their livelihoods by providing services for payment while pursuing the non-market ideals of their chosen fields (Anderson 1993: 156). Within societies Altman would characterise as market-based there are many people - scientists, artists, sportspeople, doctors and so on-whose livelihoods are enabled by institutions which mediate market and non-market norms.

One of the distinctive features of partial commodification is the recognition of standards of excellence that exist independently from 'instrumental criteria such as profitability' (Anderson 1993: 147). Partial commodification depends upon a willingness to acknowledge domains of human pursuit with intrinsic value regardless of their market value. It depends on recognition that deviation from market norms does not indicate deficiency or failure on the part of artists and scientists. Securing state funding - an important element of the hybrid economy approach - is a classic strategy for resisting full commoditisation. This requires respect by policymakers for the autonomy of separate spheres within civil society that operate 
according to their own frameworks of value (Anderson 1993: 149). It demands that the state refrain from 'regarding itself as a customer for the projects it funds' (Anderson 1993: 149), in other words, specifying what it will purchase and refusing to fund anything else. This is important for the integrity of these separate spheres.

There is always the risk that partial commodification will slide into full commodification. Greed or pressure to make a profit can compromise the pursuit of higher purposes (Anderson 1993: 147). As Michael Sandel (2012) has cogently argued, market values can displace other values when market principles are brought to bear. Vigilance is required to guard against the over-intrusion of norms from other spheres. There is a need to continually reaffirm that some goods should not be treated as mere commodities. The conditions which enable partial commodification are fragile and are threatened by market fundamentalism.

How then does this discussion of partial commodification enhance our understanding of the hybrid economy? The Venn diagram with which Altman represents the hybrid economy directs our attention to the question of whether or not an activity involves multiple overlapping spheres (Altman 2006: 2). But what really matters is the answer to a more nuanced question: How do the norms and expectations originating in the different spheres interact? In the activity under consideration, which are more powerful: market norms or customary norms? Are customary norms crowded out by market incentives? Has commodification changed the character of the activity in regrettable ways? Alternatively, do customary norms dominate in a way that makes the activity unprofitable and incompatible with making a decent living? The concept of partial commodification suggests a continuum between no commodification and full commodification. In a given activity there might be some influence of market norms though customary norms clearly dominate. In another, customary norms might prevail with a trace of market influence also evident. The point at which market intrusion becomes too great is a matter for contestation. Minds will differ as to how much compromise is worth making for the sake of generating greater income.

Altman (2010: 275) writes of the 'bliss point' of the hybrid economy. Our discussion of partial commodification clarifies that the bliss point is not simply any economic activity in which the customary, 
state and market sectors are overlapping. Indeed the three sectors can potentially overlap in regrettable ways - ways which ensure the displacement of customary norms but result in no compensating benefits. The point is that the hybrid economy potentially brings customary and market expectations into tension. Valorising the articulation of customary with market economies is too simple, and this is not what Altman intends. He insists that he does not 'seek to present this commodification of culture as unproblematic, be it in tourism, the arts or the provision of environmental services' (Altman 2010: 273). Rather he emphasises the importance of selectivity when thinking about opportunities for development. Altman is aware that the challenge is to 'nurture the hybrid economy in ways that mesh with Indigenous values' (Altman 2001: 10).

My discussion of partial commodification is also intended to draw attention to the threats to the income-generating activities that typify the hybrid economy. They depend not just on the ongoing recognition that there are autonomous spheres of such value, but that the contemporary Indigenous domain is one of these spheres. Indigenous people judge their performance of obligations to country and kin in accordance with the values internal to the Indigenous domain. It is to be expected that the standards thought most important by Indigenous producers may not fully overlap with the standards held by providers of external funds whether they are for-profit firms seeking carbon abatement services, philanthropists or the state. Outside funding creates difficulties when funders are reluctant to acknowledge the Indigenous domain as an autonomous source of value. To advocate for the hybrid economy is to struggle against the market fundamentalist mindset which refuses to honour the legitimacy of non-market norms.

\section{Conclusion}

This paper has highlighted the concerns about the market system explicit and implicit in Altman's work that have driven his search for alternative economic forms. One impetus for Altman's development of the hybrid economy approach to Indigenous development has been his scepticism that the market economy will ever deliver adequate opportunities for Indigenous people who are culturally or geographically remote from urban centres. But in this chapter I have argued that his concern about 
the social costs of moving from a kin-based to a market-based economy have also been vitally important to the development of this innovative approach. Altman fears that making the shift from a kin-based economy to a market-based economy demands a profound transformation of people's values, desires and relationships.

I have argued here that the hybrid economy can be understood as a project of alternative livelihood generation through partial commodification of goods and services deriving from the Indigenous customary domain. Assessing whether (and under what conditions) the partial commodification of particular Indigenous practices can resolve the tension Altman identifies between Indigenous cultural dispositions and the attitudes and priorities underpinning market society requires empirical research by economic anthropologists and others. Clearly political philosophy can only take us so far. Nonetheless, what I have tried to do in this chapter is show that the challenge inherent in deriving a livelihood from uniquely Indigenous practices while safeguarding the distinctive moral understandings which inform these practices has analogies in many other fields. Knowing that partial commodification does not always lead to corruption of non-market values provides grounds for optimism. At the same time we should avoid a blind celebration of hybridity. Economic hybridity threatens lose-lose scenarios just as much as it promises win-win ones. It would be a mistake to equate the bliss point of the hybrid economy with the overlapping of all three sectors. Rather what matters are 'the norms governing the production and circulation of goods' in particular contexts (Anderson 1993: 166). To know this we will need further careful empirical study of the details of local Indigenous economies.

\section{References}

Altman JC (2001). Sustainable development options on Aboriginal land: the hybrid economy in the twenty-first century, Discussion Paper 226, Centre for Aboriginal Economic Policy Research, The Australian National University, Canberra. 
Altman JC (2005). Economic futures on Aboriginal land in remote and very remote Australia: hybrid economies and joint ventures. In Austin-Broos D \& MacDonald G (eds), Culture, economy and governance in Aboriginal Australia, University of Sydney Press, Sydney.

Altman JC (2006). The Indigenous hybrid economy: a realistic sustainable option for remote communities? Topical Issue 2/2006, Centre for Aboriginal Economic Policy Research, The Australian National University, Canberra.

Altman JC (2010). What future for remote Indigenous Australia? Economic hybridity and the neoliberal turn. In Altman JC \& Hinkson M (eds), Culture crisis: anthropology and politics in Aboriginal Australia, UNSW Press, Sydney.

Anderson E (1993). Value in ethics and economics, Harvard University Press, Cambridge MA.

Austin-Broos D (2011). A different inequality: the politics of debate about remote Aboriginal Australia, Allen \& Unwin, Sydney.

Bowles S (1998). Endogenous preferences: the cultural consequences of markets and other economic institutions. Journal of Economic Literature 36(1):75-111.

Buchanan G (2014). Hybrid economy research in remote Indigenous Australia: seeing and supporting the customary in community food economies. Local Environment 19(1):10-32.

Curchin K (2013). Interrogating the hybrid economy approach to Indigenous development. Australian Journal of Social Issues 48(1):15-34.

Gill N (2005). Aboriginal pastoralism, social embeddedness, and cultural continuity. Society \& Natural Resources 18(8):699-714.

Holcombe S, Yates P \& Walsh F (2011). Reinforcing alternative economies: self-motivated work by central Anmatyerr people to sell Katyerr (Desert raisin, Bush tomato) in central Australia. The Rangeland Journal 33(3):255-65.

Howitt R (2012). Sustainable Indigenous futures in remote Indigenous areas. GeoJournal 77:817-28. 
Kwan D, Marsh H \& Delean S (2006). Factors influencing the sustainability of customary dugong hunting by a remote indigenous community. Environmental Conservation 33(2):164-71.

Lloyd C (2010). The emergence of Australian settler capitalism in the 19th century and the disintegration/integration of Aboriginal societies: hybridisation and local evolution within the world market. In Keen I (ed.), Indigenous participation in Australian economies: historical and anthropological perspectives, ANU E Press, Canberra.

Morphy F (2008). Redefining viability: Aboriginal homelands communities in north-east Arnhem Land. Australian Journal of Social Issues 43(3):381-96.

Sandel M (2012). What money can't buy: the moral limits of markets, Allen Lane, London.

Scambary B (2009). Mining Agreements, developments, aspirations, and livelihoods. In Altman JC \& Martin DF (eds), Power, culture, economy: Indigenous Australians and mining, CAEPR Research Monograph No. 30, ANU E Press, Canberra.

Smith BR (2003). Pastoralism, local knowledge and Australian Aboriginal development in northern Queensland. The Asia Pacific Journal of Anthropology 4(1-2):88-104.

Sullivan P (2011). Belonging together: dealing with the politics of disenchantment in Australian Indigenous policy, Aboriginal Studies Press, Canberra.

Watson V (2009). From the 'Quiet Revolution' to the 'Crisis' in Australian Indigenous affairs. Cultural Studies Review 15(1):88-109.

White JM (2011). Histories of Indigenous-settler relations: reflections on internal colonialism and the hybrid economy, Australian Aboriginal Studies 1:81-96. 
This text is taken from Engaging Indigenous Economy: Debating diverse approaches, edited by Will Sanders, published 2016 by ANU Press, The Australian National University, Canberra, Australia. 